\title{
Knowledge Production, Knowledge Management and the Competitiveness
}

\author{
Yusuf Kurtoğlu \\ Phd in Economics \\ Undersecretariat of Turkish Treasury \\ İnönü Bulvarı, No.36, Balgat/Ankara 06510 TÜRKIYYE \\ yusuf.kurtoglu@hazine.gov.tr \\ yusufkurtoglu@outlook.com
}

\begin{abstract}
In this paper, we examine the knowledge production and the knowledge management processes as the basic requirement of the competitiveness and innovation activities. First, we intend to analyse the causality and the required conditions, major forms and the certain stages of knowledge production. For the institutions, knowledge means institutional harmony, rules, experiences and practices and it is not receivable from the data bases, but created through common mind. Knowledge creation processes should be considered as "the initial stage of the knowledge production activities in firms that aims to create and use the tacit knowledge" parallel with the long term operational strategic plans. Secondly, dealing with 'the knowledge management system' that considered as the necessitate to implementing the efficient knowledge production process and the useful applications. Having been the sector specific knowledge in which the firm operates, gives serious advantages to the firms in an intense competitive environment. In this framework, by forming the knowledge management system, transition of the knowledge should be secured through each person in all departments in the company. The existence of functional common corporate culture effects positively to the knowledge accumulation process, and contributes consistently to facilitating the knowledge management system. The continuity in the knowledge production process that is a requirement for innovative activities, allows renewing the available knowledge stocks. This gives the clues why the knowledge production and management processes considered as the crucial stage for the companies that seeks to gain the competitiveness in international markets. Meanwhile, the efficient use of the information and communication technologies (ICTs) supports the knowledge management system also. By using the ICTs, throughout the processes of diffusing and evaluating, the cost reductions should be highly possible in terms of acquiring, accumulating and sharing the knowledge.
\end{abstract}

Keywords: knowledge production, knowledge management, knowledge spillover, tacit knowledge, competitiveness.

\section{INTRODUCTION}

Knowledge intensive human capital, works in innovation activities, functions as the major determining factor with respect to gaining competitive advantage due to the functions performed. The knowledge that created by the skilled workers during the research and development (R\&D) process, and used as an input, allows to be having increased rate of return and increased scale effect in economic activities. Thus, the economic growth rate should have affected by this process positively. Higher the share of industries dominated with the innovated or patented goods, or the industries with higher the intangible capital share implies higher the knowledge input used in economic sectors and having faster technological improvements.

In the innovation process, the skilled workers are creates new products by facilitating the knowledge stocks already have in the economy, and the knowledge received through spillover from outside sources. Once the knowledge /technology stock taken as a given variable, the only factor focusing, regarding with the economic growth policies, should be the knowledge intensive labour or knowledge input. The importance of knowledge input as a production factor, originates from higher efficiency of especially the knowledge intensive manpower that in return increases the value of final goods. Thereby, factor intensity of industries effects the market value of firms. (1)

The required conditions for improving the efficiency of knowledge input would be secure by constituting and creating the education and training opportunities for more people. Furthermore, encouraging increases in the supply of knowledge intensive human capital, gains crucial importance 
within the context of macroeconomic policies. On the other hand, having, only the relatively higher number of human capital, should not be enough to determine and/or gaining the competitive power. Additional measures are supposed to be taken for using the human sources efficiently in the knowledge production process. Producing the knowledge and to bring it about as an organizational knowledge requires interfering to the matter. Forming the required knowledge and interact with the knowledge intensive workforce and the technological installation of the company could be the major initial steps for settling the convinient working environment to facilitating the competitive advantage. Knowledge production, accumulation and sharing, not only purposed as an ordinary production factor but also supposed to be as the unique source for the firms that is secure the competitive advantage.

Because, created new knowledge brings about the differences, in the means of comparative advantages, either on the prices and qualities or to meeting the changing tastes and increased preferences of customers. (Yeniçeri and İnce, 2005:133-139) The continual increases in both accumulated knowledge and exchanged information, and ideas developed among working people, should contribute more to the efficiency of both knowledge production and knowledge management processes.

The paper is organized as follows. Knowledge production and the related matters analysed in section 2 , and then the subjects to the knowledge management is giving in section 3 . Then, section 4 deals with the concluding remarks.

\section{KnOWledge Production}

Knowledge defined as the realized facts or ideas derived from works, research, education and, observations or experiences. It has been produced or acquired either explicitly from open sources or implicitly, mainly by interaction of the working people with each other. The terms of expilicit knowledge declares absolute forms; those are concrete purports, rationalism and objectivity, such as engineering designs, product and production specifications, performans specifications, suppliers list, purchasing directives etc. Whereas, tacit knowledge comprise of the concepts such as education, private beliefs, point of view and values, experience, behaviour, common sense, adequacy, skill and intuition, mostly adhered with the personality. Krogh, G.V., and others (2000:75), gives the sources of tacit knowledge as; customers, suppliers, strategic partners, unit knowledge communities, and other organizational units, and working people are the prospective sources.

On the other hand, in Krogh, G.V. and others' study (2000:16-17), knowledge is defined as the justified real beliefs. Because it is acquired via the observations originates from the corrected beliefs. Observations reflects the private points of views and experiences also. Thereby, knowledge could be define also as structuring the real things in life rather than abstract or universally corrected things.

The knowledge for the institutions is means of the institutional harmony, the rules, the experiences and the practices and it is not receivable from the data bases, but created through common mind. While this approach is relevant either of the knowledge kinds, tacit knowledge peculiar to the company and considered as an intangible asset. (Tiwana, 2000:77, and Dervişoğlu, 2004:31) Specialised competencies and specific knowledge have increasingly become a key asset for the firm survival and growth. (Malerba, 2005:73) The requirement of the production of specific and/or new knowledge, originates from the necessitates of the renewing the current knowledge which otherwise becomes old. On the other hand, once the explicit knowledge internalized and shared, it should be add to the current knowledge capacity of the company.

Disclosure of the tacit knowledge, first of all, requires to give necessary importance to the matter that mostly depends upon to the correct approach and support of the company management. Secondly, in order to clarify and measure the tacit knowledge the required level of the communication and transparency should be settled within the firm. Within this framework, team work is accepted as one of the most effective way of revealing and sharing the tacit knowledge. Higher the efficiency on communication and dialog, increases the ability of sharing tacit knowledge. Therefore, efficiency in knowledge creation process (2), closely related with the level of attendance and the participation both of the company management, as the responsibly stand, and the workers (Krogh, G.V., and... 2000:20, 23).

This process ought to be considered as the initial stage of knowledge production, that aims to create and use the tacit knowledge parallel with the long term operational strategic plans of the company. 
Facilitating the tacit knowledge into the firm's activities such as research, development, design and production processes, should give major support to the accumulation of "the knowledge input as a production factor".(3) Accordingly to the assumptions of endogenous economic growth theory; the more people attends to reveal the tacit knowledge, the more "knowledge factor' should have employed in the firms' activities. Then, following this approach, the increased expectations to the achievement of innovated products supposed to be ensured in following periods.

Introduction of "innovative knowledge input" into the R\&D process, could cause to increase the possibility of creating and acquiring the new products which discrete and having competitive advantage. Within this range, tacit knowledge by possesing "the increasing rate of return to scale", could be acceptable as the basis of 'the firm specific knowledge' that empowers the competitiveness. This makes the knowledge input's role crucial, as the major determining production factor of the competitive power in 'knowledge intensive industries and sectors'.

This effect originates from the peculiarities of the 'knowledge input', that is the only production factor, increases as it is used and shared. As the number of users rising, the knowledge become standardized and have increasing value. By using the same knowledge more than one time, the amount of return we get rises that it has allows "the increasing rate of return" (Dervişoğlu, 2004:16, 17 and Tiwana: 67, 68, 111). Some supporting figures given in Bottazzi and Peri' (2005:29) research that a $1 \%$ positive shock to the log of R\&D in United States (U.S.) increases the knowledge creation in other countries by an average of $0.35 \%$ within ten years. The same shock generates a maximum 6 $\%$ effect on the U.S. stock of knowledge after five to ten years and then declines slightly. Besides, in recent growth models of Nahuis and Smulders (2002), and Ellis and Roberts (2002), the marginal rate of return to the knowledge input taken higher than the ones physical capital and labour factors employed in conventional industries.

In the steady state conditions, the knowledge input has decreasing rate of returns. To turn this fact on the reverse side, the knowledge ought to be renewed in time. If the knowledge had not produced continuously, the goods and services produced with the large expenses should be faced with the risk of 'become obsolete' in a short time." (Yeniçeri and İnce, 2005:259) Renewing the knowledge, requires continuity in the knowledge production. This necessitates to implement 'the knowledge management system' as the supplementary part of the knowledge production activities. Because, the management system should contribute positively to the improvements of the human capital's efficiency which the major source of the knowledge input.

In this stage, the question is that "how the knowledge production process could enhance the innovations". The answer lies on the combined activities that facilitates creating new marketable products during R\&D process. The matter disscused in Schulze (2003), and emphasized as the created usefull knowledge that should be able to increase the performance, enhance the customer satisfaction, create new capacities and encourage innovations. The corporate policies related with 'the knowledge production' should be targeted to improve the creativity as it contributes to the rise in competitiveness in the long-term.

\subsection{The Required Conditions of Knowledge Production}

Coherent with the theoretical assumption to consider the knowledge as a production factor; such questions of "what kind of knowledge and how to produce", "what should be the sources, conditions and ways of production" ect., comes to the company management' agenda. While searching the answers to these questions; firts of all, the 'knowledge production process' and related conditions ought to be taken as a vision. Following this, some other requirements supposed to be fulfilled. For example, the process might be comprise of a good managed communication process, in which some knowledge activists included. Then, forming the convenient environment requires to encourage use of the explicit knowledge from outside sources, and contributes to the accumulation of knowledge as well. (Krogh, G.V. and others, 2000:123-126, 211, 269.)

Further statements to the knowledge production conditions given in following sections of our study.

\subsubsection{Adaptation of Knowledge Support as a Vision}

In principle, adaptation of the knowledge production action as a vision, should encourage and incline the workforce with the strategic plans of the company. Such an approach could ensure the workforce to feel himself as a part of the broader framework of the company. The vision' concept supposed to 
involve not only the current technologies but also the new science fields, expected technologies and the fields necessitates specialization in the future. Besides, knowledge vision might be indicated that what kind of knowledge the workforce might be searched and produced. When the managers ensure to develop an efficient knowledge vision, it could ease to compose of the micro groups in which the attendance supposed to express and exchange the ideas to each other. Then, the following stage the more knowledge diffusion throughout the company should be possible. The vision document, by determining the kind and concept of the required knowledge to produce, should have explain the open and clear direction to follow for the micro groups members in the company. The desired outcomes received from the knowledge production activities should be related closely with in what degree the knowledge production process taken into consideration as a vision and became institutionalized.

\subsubsection{Management of Communication}

Settling the communication system within the certain range in a productive group could contribute to the improvements in individual creativity and provide the produced knowledge in excess of the level that provided by the unique brain. Bringing the individual ideas and actions together would be possible just through communication and mutual interaction. On the other hand, the efficient 'knowledge production support system', requires attandance of all the working people to the creative activities in the company. Therefore, the extent and the good management of the communication process, to the mean of supporting the knowledge production activities, could be formed as a crucial matter. The subject is going to examine further, in $3 \mathrm{rd}$ section.

\subsubsection{Actions of the "Knowledge Activists"}

Existence of the knowledge activist and well organized working conditions ensures the stability for knowledge production supporting initiatives in the company. Knowledge activists, first of all, settles the coordination of different knowledge production initiatives, secondly, establishes the micro groups, helps to communication, and determines the conditions how the participants could share the knowledge in a proper environment. Thereby, the "activists", by diffusing the knowledge production process through different departments and contributing to the participants' efficiency increases, ensures reductions in both of the costs and time spended in the firm.

\subsubsection{Forming the Convenient Environment}

Since, the communication and interaction between working people is crucial in the knowledge production process, forming the favourable environment contributes more to sharing initiatives of the experiences and point of views. Settling such an atmosphere, by creating care, confidence and stability in working conditions, is under the authority and responsibility of the company management. The organizational structure, in order to meet the requirements of knowledge production supposed to be consistent with either existing operations or for future market plans, and coherent with the interaction conditions and communication facilities. Once such an environment organized, 'the good managed knowledge production process' should create an important opportunity to contribute gaining the sustainable competitive advantage.

\subsection{Major Forms of the Knowledge Production}

The major forms of the knowledge production for the enterprises, is given as the followings: (Kalkan, V.D., and others, 2005)

- "Organize and/or attend the training cources and seminars for the workforce of the company,

- If required, buying the crucial knowledge from outside sources,

- When it's necessitated employ new people who have desired knowledge that the firm lack of,

- Collaboration with the universities and other research centers for realizing the joint research and development investments,

- For making comparison with the other firms, follow the rival companies' innovation activities properly.

- Making regular communication and collaboration with professional associations." 
It should be emphasized that the above mentioned knowledge production forms mostly related with the explicit knowledge rather than the tacit ones that's going to examine in the next section.

If we put the knowledge production determining variables into an equation which includes both explicit and tacit knowledge could be written as;

$\mathrm{KP}=\mathrm{f}((\mathrm{KCs}+\mathrm{Sp}(\mathrm{edu}$, tra, buy, uni, riv $)) 2.1$

where,

KP; represents the knowledge production process,

KCs; refers to knowledge capital stocks,

$\mathbf{S p}$; is the spillover effect of explicit knowledge received from outside sources,

Edu; refers to the skilled human source that employed and have desired knowledge,

Tra; is meant the training activities given to the workforce,

Buy; means that the special knowledge recieved explicitly, due to the requirements,

Uni; is meant the realized collobration with universities and research centers,

Riv; refers to the rival firms operating in the same sector those have innovative activities to be fallowed by.

\subsection{Certain Stages of Knowledge Production}

\subsubsection{Knowledge Spillover and the Effects}

The knowledge spillover process comprise of the variety of materials from which physically written documents such as reports, desings, models, etc. to meetings and other ways of communications, especially to the ones using throughout the information and telecommunication technologies. Within this context, either bilateral diffusion of knowledge among different departments in the company or exchanging the knowledge with the other stakeholders such as suppliers, customers, rival firms and individuals, should contribute and effects positively to the knowledge production process.

Information flows among the producers of different input and/or technological final goods would have reasonable positive effects on accumulation of the knowledge stock, due to the complementarity of supply and demand conditions. This, in return, provides convenient environment for supporting the innovative research and development activities, and the improvements in the production process, organizational structure, and marketing. Higher the complementary of spillover effects, higher the contribution should have been to the knowledge production process.

Then, how the spillover process should work well or what to do for a desired running process. In order to contribute more to the convinient spillover process; the actions, such as nominating the specialized personnel with the task of supporting the knowledge production in different departments and forming a close cooperation among the working teams, ought to be taken concurrently. Besides the existing level of 'knowledge intensive human capital', the speed and the efficiency of diffusion, should be related closely with the good knowledge management operating system within the company.

\subsubsection{Sharing the Tacit Knowledge}

Sharing the tacit knowledge should have accepted as the first and indispensable stage of knowledge production process. Forming the proper atmosphere ought to be considered as the initial condition for an efficient and productive knowledge production system which in turn affects the efficiency of the tacit knowledge sharing process in the micro woking groups. Existence of the convenient environment, with higher level of confidence is crucial for the sharing process of the tacit knowledge that the group members personelly have. Besides the creation of such supportive environment in general, the responsive relationship in the micro groups and widening this consistency into the larger groups, supposed to increase the expected efficiency of the tacit knowledge sharing process.

Communication in groups, within the context of the relevant specified subjects, ranges from talking on individual dreams to reflection of the simple personel ideas. At this stage, the participants becomes better known each other during face to face discussions. Thereby, this process contributes positively to sharing the personel knowledge among the participants. Exchange and discussing the ideas, gives 
opportunity for the group members, to think over different opinions and searching new ideas. Such an environment could provide proper conditions to either first and the most important stage of knowledge production or sharing the tacit knowledge in the micro groups.

Supporting the active participation in the group, by defining and emphasizing specification of the knowledge that supposed to be produced, is an important requirement to reaching the planned and expected targets. Participation into the group activities contributes bilateraly to the attendants in the means of benefiting better from the tacit knowledge sharing process which acquired by a particular department. Hence, it would be possible to combine and integrate the knowledge by transfering between different departments in the company. Otherwise, it could hardly be possibble to use the produced knowledge in each department. Without participation and with the uncertainity, the real value of 'the produced knowledge' should reduce, whereas exchanging the projects between departments seen as a crucial requirement for the innovation processes. Therefore, the preferable policy, related with the knowledge production and sharing activities, ought to be the one that the company management must collaborate and encourage the personnel rather than forcing the people. (Krogh, G.V. \& others, 2000:102, 145-155, 178, 204, 208, 230-235)

If people gathered in the groups accordingly with their own knowledge and capability, this contributes more to produce the new knowledge, because the specific knowledge which it could produce with the interaction between group members. Exchanging opinions between technicians, experts and other personnel, working in different departments, makes possible to saving time and cost reductions via the contribution of previous experiences shared. The continuity in communication among working people, assure acquiring the new ideas, the new knowledge and the new data that secure to receive warning signs and than gives opportunity to taking the necessary actions timely to searching the problems which faced and prevents the required improvements on firm operations.

Within this context, the company management supposed to give the required attention and understand the importance of supporting the knowledge production process and sharing tacit knowledge, due to spillover effects, and the innovations which originated from individual researchers who works mostly within the team. Thereby, the evident discussions in the group and sharing tacit knowledge with the other working people, could prepare the concrete base for the innovations and new business opportunities.

Related with the knowledge production and sharing process, not only the management structure and internal relations of the company but also the external relations plays important function. For example, the policy implications that executed during the internal knowledge sharing activities supposed to involve the measures to meet the real needs of the customers timely as well.

Close cooperation including sharing the tacit knowledge with the customers should result with "a renewal union" between contracting parties. This result occurs because, regular and face to face meetings with the customers creates a good atmosphere for generating the bilateral convenience and reliance. Similarly, design a close relationship with the other stake holders such as creditors and suppliers to the mean of knowledge sharing, should contribute positively on the knowledge production process either. The communication with a wide range of participants could form the convenient environment to clarifying the personel ideas, desires, and plans for the future. And this contributes to deepening "the firm specific knowledge" within the context of the scope and the content.(Krogh, G.V. \& others, 2000:94, 96,174, 177, 209, 212, 218, 225, 227).

On the other hand, sharing and using the tacit knowledge would have some natural obstacles and limits, originating from its' definition. Tackling of these obstacles and limits would possible, barely with a good management system that is the main subject of the following section.

\section{KNOWLEDGE MANAGEMENT}

Increased demand to the knowledge input "as a production factor" originates from the requirements of having been sustainable competence, and gaining competitive power. The competitive market structure force the firms to operate as efficient as these dynamic conditions necessitates, coherent with the changing in competitive environment. Efficient operation of the knowledge management system could secure to facilitate the individual capabilities of the working people better which in turn contributes to the competitiveness of the firm. Personel ingenuities, with the support of interaction, communication and transparent policy implications, should be turned into organizational success in 
which the individual knowledge becomes the corporate knowledge (Dervişoğlu, 2004:51 and Tiwana, 2000:22). The success of the knowledge management system, gained with the facilitating of the existing working capabilities, should reflect to the overall performance of the company and add as the created values. Because, creating values in the knowledge production process from beginning up to the implementing stage, supposed to be related closely with the efficiency and success of the knowledge management system. This achievement arise as "the firm specific knowledge" that have been hidden within the daily working plans, models, organizations, processes, and practises in the corporates.

Continous developments in innovative activities, related with the goods and services should provide further increases to the number of rival firms in the markets. As a result of this process, faster the goods and services becomes obsolote. Thereby, how it should be possible, for the firms, to tackle with this problem. Within this context; firts of all, creating and forming the new knowledge as it required and secondly, sharing and applying that knowledge into the production process, coherent with the planned mission, becomes the major essence of success for the companies. The knowledge management process supposed to comprise of the action plans that secure use of the knowledge parallel to the organisational aspects (Yeniçeri and İnce, 2005:64-65). The importance of having been 'a good knowledge management system' comes to the agenda in this stage. Because, determining the available knowledge that sufficient for the current activities, and the plans for the future is a necessity in terms of the knowledge accumulation process.

As part of the corporate culture, the knowledge management system requires transmit the knowledge to all of the personel works in each department of the company. A desirable knowledge management strategy obliged to provide exposing and partition of the both explicit and implicit knowledge with related parties. This is a phenomenon, works bilateraly for either sides of the company and the participating personnel that emanated from complementary requirements between the company development plans and adequacy of the work force. Such a knowledge management process could ease to reach the planned target and then, the knowledge become institutionalized.

The existence of functional common corporate culture effects positively to the knowledge accumulation process, and contribute consistently to facilitating the knowledge management system. Having been a good knowledge management system would secure acquiring the required knowledge, such as the necessary information about the rivals, changing competition environment and market conditions, and use it timely. Within this context, the crucial task for a company, is to manage the knowledge consistently in order to create difference in the means of gaining the competitive advantages (Tiwana, 2000:17-19, and 113-124).

To secure this, the good knowledge management system is considered to provide;

- Timely and better decisions on operations,

- Improve the effectiveness of the knowledge intensive manpower in the company,

- Secure the improvement in competence via efficiently facilitating the contribution of the knowledge production process,

- Better services to the customers.

The importance of knowledge management comes from the outcomes derived in which presents also whether the knowledge production process utilized as effectively as it could or not. The success in implementation of the knowledge management system contributes more to the accumulation of "firm specific knowledge input". The benefits of the effective use of knowledge, as the main aspect of knowledge management system, should be specified as the followings;

- Settlement of the policy to support the knowledge management system as a vision, helps more to diffusion of the knowledge throughout the company,

- This stimulates searching and revealing the scope and kind of knowledge production which most required for the company' current and future operations, 
- Then, parallel with the such correct policy implications, the possibility of effectiveness should increase, in the means of innovating new products, intending to introduce these goods to the new customers with the aim of expanding the market share further.

But, how it could be possible to set up such a required system of knowledge management. The instruments related with the knowledge management policy specified in Kalkan, V.D. and others (2005), as the followings;

- Determine the required knowledge,

- Setting the knowledge support programs and unit knowledge groups,

- Searching the fundemental determinants of competition,

- Evolution of knowledge use and new knowledge production policies parallel to the competitive capacity targets,

- Partition of knowledge among all of the working people.

\subsection{The Effects on Knowledge Production}

The company management ought to be the responsible authority to produce and efficient use of the knowledge. To assemble, maintain and improving the required conditions for knowledge management process, including organisational/physical infrastructure, stands as an obligation to the board of managers and/or the responsible committee managers in the company.

What to do for the improvement and renewing the knowledge production process and to increase the accumulated firm specific knowledge. What should be the effect of knowledge management system on this process. As it's emphasized in Krogh, G.V. \& others (2000:88-89), the effects of knowledge management to the knowledge production process occurs in two different ways: First of all, a good knowledge management system allows to explore using of the potential 'firm specific knowledge' through value creation activities. Secondly, the managers ought to use the knowledge either produced and belongs only with the company or the knowledge received from the external open sources. Whichever sources the knowledge received and/or produced, it have to be used more efficiently than the rival companies. This argument, originates from the companys' profitability that suppose to be above the sectors' average in which they are operating, to secure staying in the market. Continuous improvements in the knowledge production and to put it in practice is necessary not only being able to stay in the market but also for increasing the market share in the future.

Therefore, the crucial question to be asked is "how the knowledge production process should be managed?". Continuity in learning efforts suppose to be the major priority with respect to the improvements in knowledge production and knowledge management activities. However, there might be some constraints related with the learning. For example, according to Malerba, (2005:65) "learning behavior and capabilities of agents are constrained and bounded by the technology, knowledge base and institutional context in which firms act."

The knowledge base and the institutional structure supposed to be directed, managed and improved, in generally, by the board of managers of the company. Within this context, in order to improve the efficiency of the knowledge accumulation process and structural reorganization in company, via forming the convenient knowledge management system, plays cruial role. Such a knowledge management structure ought to be settled in order to realize the required knowledge production process that supposed to comprise of "the good management of quality control, inventories, personnel, individual relationships, common practices, feelings, regular communication with suppliers, customers and other stake holders".

On the other hand, increased efficiency in knowledge management system, respect to the supporting the knowledge production, should be closely related with the successful implementations of the knowledge production activities. For example, exchanging the knowledge timely and regularly, makes to find faster solutions for the problems faced during the production processes. Because, communication and collaboration contributes more to the creative activities. Otherwise, strict controls or inhibitions on the knowledge exchange and/or circulation between company management and workers at any level, should cause some serious disturbances on the business administration, 
production and marketing operations. Applied open source policies throughout the departments such as finance/accounting, marketing, production, etc., those are the main knowledge sources at the organizations, should help to find out the necessary information for the daily activites in the company. Thereby, if there is excess knowledge it could exposes also, or the reverse should be relevant. Thus, each department should be expected to work in a big convenience parallel with the vision of the company which in turn makes crucial contributions to the realization of the companies' strategic plans. (Krogh, G.V. \& others, 2000:20-25, and 40).

\subsection{The Impact of Information and Communication Technologies}

Organizational restructuring in general and using the information and communication technologies (ICTs) particularly, as part of the reorganizational process, should affect positively the efficiency of knowledge management system.

Parallel to the increased communication facilities with technological improvements and the decreasing cost, the possibilities of ICTs' operational integration in the larger organizational structures has been enabled. In Yeniçeri and İnce, (2005:145) the human capital and ICTs are stated as the most important contributing instruments to the knowledge forming process. Once such an operational integration and collaboration brought about either among the working people or between the company management and the suppliers, and the customers, the increased efficiency improvements supposed to be achieved in the overall activities of the firms. Otherwise, with the relatively limited, and time consuming information flows and communication services, deterioration and reversing the efficiency should be inevitable.

Besides, using the ICT instruments in the activities such as the knowledge production/spillover and the R\&D operations, within the required ranges of cost reduction and information sharing, contributes more to the efficiency of knowledge management structure. During the R\&D operations, due to the requirement of searching new innovative opportunities in detail, there should be requirements for the large amount of purchases and the longer time to spend. First ICT using provide, increased volume of availability and processing of required knowledge, and secondly it secure cost reductions of the facilities and requisites such as the communications, design and engineering studies, and planning the business programmes. The positive contribution of ICTs on firm's overall activities could happen via transfers of the available knowledge and using faster and wider communication facilities, including operational network systems of intranet and internet. As a result, ICT using assures time saving in operational activites and having increased efficiency in solving the complicated issues, and the new projections for either the R\&D workers or the knowledge managers.. Thus it would be possible to have fewer working hours spent for the same amount of knowledge acquired and/created, and then increased unit labor productivity and efficiency, which in turn contributes to the competitive power positively.

The effectiveness and the major utilizing areas of the ICTs which increases the efficiency of the knowledge management and the knowledge production processes, should be given as the followings:

- Receiving, buying and accumulating of the knowledge,

- Exchanging the views, ideas, and inventions, among wider range of working people in the organisation,

- Controlling, analyze and processing daily operations of production and marketing activities, respect to securing the quality and productivity increases of manpower, and seeking the competability,

- Communicating with the suppliers and customers for improving the goods and services have already producing, for satisfying the changing preferences and desires of the customers,

- Works for the future plans and the related changes to determine the vision.

\section{Concluding Remarks}

The continuity in the knowledge production process, secure renewing the available knowledge stocks. That's the reason why the knowledge production process considered as a crucial stage for the 
companies. This argument should be relevant with respect to not only the range and qualifications of the participants but also the concept of the knowledge production process.

Having been the specific knowledge about the product, the production process and the market, by contributing to the innovation process more, makes possible the firms to gain comparative advantage, and to be in advance among the rivals. Meantime, even being different in the means of product or services, make for the firms to create increased values in the overall activities. The compatible way of the creativity and the difference should have need "the required level of creative knowledge input" which is the only production factor make possible to realize the innovations.

Tacit knowledge which is formed mostly with the contribution of skilled human capital, is accepted as the basis of 'firm specific knowledge' that strengthen the competitiveness. As the disclosured tacit knowledge accumulated, forming "the firm specific creative knowledge" supposed to be increase as well. Within this context, the actively participated job-site training and exchanging the views in knowledge production process contribute to the improvements in in both of the firm specific knowledge base and the product quality. Thus, it could be said that higher the 'specific knowledge' created, higher the institutionaly achieved competitiveness.

Such outcomes enriches the policy of which to adapt the knowledge production process as a vision.. Such a vision might support to improve the competitive advantages with respect to the price, quality and customer satisfaction. In this stage, establishment of a good knowledge management system play crucial function either to the facilitating the required knowledge production process and implementation of the produced knowledge through planned directions.

\section{APPENDIX}

\section{The Credibility Indicators and the Competitiveness}

While the lower costs and economies of scale, in terms of conventional manufacturing goods, were adequate factors to having beeen the competitive power for the previous decades, they gradually becomes inadequate for the recent two decades. Continuous increases in competitive environment and faster changes in technology and communication facilities have bring about the agenda to take some additional obstacles and to use the new tools for having been the competitive power. The innovated products, by comprising the most recent developed technologies, creating higher value added, and decreasing production costs, has turn up as an indicator of the goods that have the competitive power. Thereby, innovations secure not only the quality and price advantages, but also submit respect to the changing tastes and increased preferences of customers, the supply of technologically renewed and differentiated products.

The realization of these three fundemental competitive power indicators concurrently; i.e. higher quality, lower price and customer's satisfaction, obliges the firms to direct and concentrate on innovations of which depends upon to the yields of R\&D activities generated with the contribution of knowledge input as the major value creating production factor. This indicates that the essence of basic determining conditions of competition, compare to the previous decades in where the conventional industrial sectors were the major engine of the economic growth, has been changed aside the knowledge factor in current decade.

Thus, the measurement indicators of the competitiveness, performance and the credibility has changed accordingly to the content and structure of the production factors. Different from the conventional manufacturing sectors, the intangible assets such as the $R \& D$, the patents, and the software purchases become the major values as the measurement indicators for the sectors 'the ones use knowledge input intensively'.

\section{NOTES}

[1] The measurement and credibility indicators of Knowledge Intensive Industries is going to analyse in appendix.

[2] Increased efficiency allows improvements in creative ideas and innovation related activities.

[3] For further discussion on 'knowledge input' see Kurtoğlu 2006.

\section{REFERENCES}


Albors, G. Jose (2003), "Tacit Knowledge Management in a SME Environment: Building the KnowHow Repository - A Case Study," Management of Technology: Growth through Business Innovation and Entrepreneurship, Edited by; n Max Von Zedtwitz, Georges Haour, Tarek M.Khalil, Louis A. Lefebvre, (Der) Pergamon An Imprint of Elsevier Science, Amsterdam 2003.

Bottazzi, Laura and Giovanni Peri (2005), "The International Dynamics of R\&D and Innovation in the Short and in the Long Run," National Bureau of Economic Research, Working Paper 11524, July, 2005.

Çapar Bengü (Başkent Üniversitesi İletişim Fakültesi), "Bilgi: Yönetimi, Üretimi ve Pazarlanması." (Knowledge: Management, Production and Marketing) received from www.bilgiyonetimi.org. On 7th December, 2005.

Dervişoğlu, Gökçe H.(2004), “ Stratejik Bilgi Yönetimi,” (Strategic Knowledge Management) Dışbank Kitapları-8, 1.Basım, Rota Yayın Yapım Tanıtım Tic.Ltd.Şti.(The Publisher), Eylül 2004.

Ellis, Huw-Lloyd and Joanne Roberts (2002), "Twin Engines of Growth: Skills and Technology as Equal Partners in Balanced Growth," Journal of Economic Growth, 7,87- 115, 2002.

Ertuğrul Murat (Anadolu Üniversitesi), "Bilgi Çağında İşletmelerin Yeni Kaynağı: Entellektüel Sermaye," (New souce of corporations in knowledge age: Human Capital) received from www.bilgiyonetimi.org. on December 8, 2005.

Estevao, M. Marcello (2004), "Why Is Productivity Growth in the Euro Area So Sluggish?," International Monetary Fund Working Paper - European Department, October 2004.

Graham, J.H. Stuart and C. David Mowrey(2004), "Submarines in Softwarw? Continuations in US Software Patenting in the 1980s and 1990s," Economics of Innovation and New Technology, 2004, Vol.13(5), July, pp. 443-456.

Gu, Wulong and Jianmin Tang(2004), "Link Between Innovation and Productivity in Canadian Manufacturing Industries," Economics of Innovation and New Technology, Vol.13(7), pp.671686, October 2004.

Kalkan, Veli Denizhan (GYTE İşletme Fakültesi Strateji Bilimi Bölümü), Ali Ekber Akgün (GYTE İşletme Fakültesi Strateji Bilimi Bölümü), Halit Keskin (GYTE İşletme Fakültesi), "Bilgi Yönetimi ve İnsan Kaynakları Yönetimi: Literatür Değerlendirmesi ve Gebze'deki Üretim İşletmelerinin İnsan Kaynakları Departmanlarında Bir Uygulama Çalışması," (Knowledge menegement and human source management) received from www.bilgiyonetimi.org. On December 15, 2005.

Keely, Louise C.(2002), "Pursuing Problems in Growth," Journal of Economic Growth, 7, 283-308, 2002.

Krogh, Georg Von, Kazuo Ichijo and Ikujiro Nonaka (2000), "Enabling Knowledge Creation, Bilginin Üretimi” /Translation-Günhan Günay, Dışbank Kitapları-1, Rota Yayın Yapım Tanıtım Tic.Ltd.Şti.-İstanbul/Türkiye, (The Publisher), 1.Basım, Aralık 2002.

Kurtoğlu, Yusuf (2006), "Knowledge Input as a Production Factor and the Competing Power", Turkish Economic Foundation - International Economics Conference on September 11-13, 2006, in Ankara-Türkiye.

Mailath, George J., Volker Nocke and Andrew Postlewaite (2004), "Business Strategy, Human Capital, and Managerial Incentives," Journal of Economics \& Management Strategy, Vol.13, No.4, Winter 2004.

Malerba, Franco (2005), "Sectoral Systems of Innovation: A Framework for Linking Innovation to the Knowledge Base, Structure and Dynamics of Sectors," Economics of Innovation and New Technology, 2005, Vol.14 (1-2), January-March, pp.63-82

Nahuis, Richard and Jack Smulders(2002), "The Skill Premium, Technological Change and Appropriability," Journal of Economic Growth, 7, 137-156, 2002.

Nahuis, Richard (2003), "Knowledge, Inequality and Growth in the New Economy," Edward Elgar Publishing Ltd., Cheltenham, UK, Northampton, MA. USA, 2002.

O’Donoghue, Ted and Josef Zweimüller(2004), "Patents in a Model of Endogenous Growth," Journal of Economic Growth, 9, 81-123, 2004. 
Samuelson, Larry (2004), "Modeling Knowledge in Economic Analysis," Journal of Economic Literature, Vol.XLII, pp.367-403, June 2004.

Schulze, Anja (2003), "Knowledge Management in Innovation Processes, Management of Technology:Growth through Business Innovation and Entrepreneurship," Edited by; n Max Von Zedtwitz, Georges Haour, Tarek M.Khalil, Louis A. Lefebvre,(Der) Pergamon An Imprint of Elsevier Science, Amsterdam 2003.

Tiwana, Amrit (2000), “The Knowledge Management Toolkit (Bilginin Yönetimi)," Translation: Elif Özsayar, Dışbank Kitapları-5, 1.Basım, Rota Yayın Yapım Tanıtım Tic.Ltd.Şti. (The Publisher), Ağustos 2003.

Ülkü, Hülya (2004), "R\&D, Innovation and Economic Growth: An Empirical Analysis," International Monetary Fund Working Paper - Research Department, September 2004.

Yeniçeri, Özcan, Mehmet İnce (2005), "Bilgi Yönetim Stratejileri ve Girişimcilik (Knowledge Management Strategies and Entrepreneurship)," IQ Kültür Sanat Yayıncılık (Publisher), İstanbul, Aralık 2005.

Zaim, Halil (İ.Ü. İktisat Fakültesi, Çalışma Ekonomisi ve Endüstri İlişkileri Bölümü), "Bilgi Yönetimi Süreçleri." (Knowledge Management Stages) received from www.bilgiyonetimi.org. On December 16, 2005. 